\title{
Competition and price discrimination in the market for mailing lists
}

\author{
Ron Borzekowski • Raphael Thomadsen • \\ Charles Taragin
}

Received: 11 January 2008 / Accepted: 23 January 2009 / Published online: 13 February 2009 (C) The Author(s) 2009. This article is published with open access at Springerlink.com

\begin{abstract}
This paper examines whether mailing list sellers, when faced with additional competitors, are more likely to try to segment consumers by offering additional choices at different prices (second-degree price discrimination) and/or offering different prices to readily identifiable groups of consumers (third-degree price discrimination). We utilize a dataset that includes information about all consumer response lists derived from mail order buyers (i.e. lists derived from catalogs) available for rental in 1997 and 2002. Our results indicate that increased competition leads to an increased propensity to price discriminate along each of the dimensions we investigate. These results hold for both second-degree and third-degree price discrimination. Further, list owners offer menus with more choices in more competitive markets. These
\end{abstract}

\footnotetext{
The authors would like to thank Peter Rossi and our two anonymous referees for their advice in improving the paper. Our gratitude as well to Meghan Busse and Avi Goldfarb, and seminar participants at Clemson, Stanford, Melbourne Business School, the United States Department of Justice, UC-Davis, the Econometric Society North American Winter Meetings, SICS, the IIOC, and the Kellogg School of Management Marketing Camp. The views expressed in this paper are those of the authors and do not necessarily represent those of the Board of Governors or the staff of the Federal Reserve System, or those of the United States Department of Justice.
}

R. Borzekowski

Federal Reserve Board, 20th \& C Street NW, Washington, DC, 20551, USA

R. Thomadsen $(\varangle)$

UCLA Anderson School of Management, 110 Westwood Plaza,

Suite B411, Los Angeles, CA 90095-1481, USA

e-mail: raphael.thomadsen@anderson.ucla.edu

C. Taragin

U.S. Department of Justice, 600 E Street NW, Suite 10000 Washington, DC, 20004, USA 
results, taken together with results from other empirical studies, suggest that the connection between competition and increased price discrimination is a result that applies broadly.

Keywords Price discrimination - Competition • Direct marketing $\cdot$ Segmentation

JEL Classification $\mathrm{D} 21 \cdot \mathrm{D} 40 \cdot \mathrm{L} 11 \cdot \mathrm{L} 86 \cdot \mathrm{M} 31$

\section{Introduction}

This paper examines whether mailing list sellers, when faced with additional competitors, are more likely to try to segment consumers by offering additional choices at different prices (second-degree price discrimination) and/or offering different prices to readily identifiable groups of consumers (third-degree price discrimination). We analyze this question empirically, because theory states that increased competition can either enhance or diminish the incentives to price discriminate.

The mail order catalog industry proves to be a useful setting in which to assess the relationship between price discrimination and competition. Because mailing lists are pure information goods, they have zero marginal costs. Hence, any price variation cannot be attributed to cost differences and must therefore be attributed to variations in demand. Furthermore, we posit that pure information goods are likely to exhibit price discrimination: Sellers of information goods generally have the capacity to price discriminate because one of the necessary conditions for price discrimination - that resale or transfer of the good be limited-is also a necessary condition for functioning information markets (Arrow 1962).

The results indicate that increased competition is associated with an increased propensity to price discriminate for both second-degree and thirddegree price discrimination. Further, list owners offer menus with more choices in more competitive markets; not only are lists in more competitive segments more likely to price discriminate in more ways, they will also partition their products into finer subsets along each dimension of the product space.

\subsection{The meaning of price discrimination}

Because the term is sometimes used in different ways, we begin our discussion by defining price discrimination, and in particular, its meaning in the context of the mailing list industry. While some textbooks define price discrimination as occurring when "two units of the same physical good are sold at different 
prices," practitioners have found this definition unsatisfactory (Tirole 1988). ${ }^{1}$ For example, many activities that are given as classic examples of price discrimination, such as charging much higher prices for first class airplane tickets than coach class tickets, violate this definition. Thus, more-recent analysis has defined price discrimination as selling similar goods at different prices in order to extract consumer surplus. This evolution of the definition of price discrimination has been gradual. In his book, Stigler (1952) states that a firm price discriminates when the ratio of prices is different from the ratio of marginal costs for two goods offered by a firm. More recently, Stole (2003) has advanced a broader definition that "price discrimination exists when prices vary across customer segments [in a way] that cannot be entirely explained by variations in marginal cost." 2 Our paper uses this more-modern definition of price discrimination.

In the mailing list context, second-degree price discrimination is implemented through the use of 'selects,' or subsets of the list. A mailing list offering selects offers the buyers of the list the opportunity to purchase either the base list at some price or a subset of the list (for example, just the female names) at a premium (the nature of the actual subsets is discussed in greater detail in Section 2.1). Each list may offer one select or many. Classifying these selects as price discrimination is justified since the marginal cost of all products is zero. We can therefore interpret firms' offering of additional products at prices different than the price of the base list as price discrimination.

We study the link between competition and price discrimination by examining the decision to offer each of the possible selects. Under this approach, the decision we analyze is not the decision to offer one or more selects relative to offering none. ${ }^{3}$ Rather, regardless of what other selects are offered, we treat the provision of an additional select as price discrimination. Further, in this paper, we consider offering more selects from a given list as indicating 'more' price discrimination.

\subsection{Previous literature}

Early price discrimination literature focused only on price discrimination by a monopolist. However, Katz (1984) and Borenstein (1985) present models that demonstrate that price discrimination can occur in free-entry markets. Shepard (1991) empirically verifies that price discrimination is consistent with competition by showing that variations in the prices of different grades of gasoline can not be attributed to cost, and thus constitute price discrimination

\footnotetext{
${ }^{1}$ While Tirole offers this definition, he very quickly goes on to discuss its shortcomings.

${ }^{2}$ See Stigler (1952), Tirole (1988), Varian (1989), Stole (2003), and Clerides (2004) for more detailed discussions.

${ }^{3}$ Indeed, almost all lists offer selects on some attributes-even if they do not offer any of the selects that we focus on. For example, most lists offer geographic selects.
} 
in a fairly competitive market. Similarly, Graddy (1995) finds that third-degree price discrimination occurs even at the very competitive Fulton fish market.

Having established these facts, subsequent research began focusing on the question of how competition affects incentives to price discriminate. ${ }^{4}$ The ensuing theoretical literature shows that competition can either increase or decrease these incentives.

The logic of why competition can decrease the propensity to price discriminate focuses on the fact that market power is necessary for price discrimination: if competition is intense enough then there is little room for firms to price above marginal cost. Thus, the logic goes, if firms have less market power they will have less ability to price discriminate. ${ }^{5}$ Further, if there are fixed costs associated with price discrimination - as exist in the mailing list industry - then competition can reduce price discrimination because the number of consumers allocated to each pricing level can become too small to support the fixed costs. This latter effect is modeled by Seim and Viard (2004). These two effects both imply that increased competition makes it more difficult for firms to price discriminate.

However, competition can instead lead to increased price discrimination for at least two reasons. First, competition can increase the dispersion of the willingness-to-pay among consumers for a particular firm's product. Second, the presence of fixed costs of price discrimination can lead to a prisoner's dilemma where each list discriminates, even though all firms would be better off if they could commit to less price discrimination.

An example of how competition can increase the dispersion of willingnessto-pay is nicely illustrated using a model by Chen et al. (2001). In their model, some consumers are loyal to one firm, and other consumers always purchase from the firm with the lowest price. Both sets of consumers have identical reservation values, so a monopolist would charge both sets of consumers the same price equal to their reservation value. However, once a competitor enters, the equilibrium outcome is that the firm should engage in third-degree competition and charge loyal consumers a high price and switchers a low price. Similarly, Dogan et al. (2008) use a model where consumers have different sensitivities to product differentiation to show that rebating (second-degree price discrimination) can become profitable with increased competition. VillasBoas and Schmidt-Mohr (1999) show a similar effect in a different setting: they demonstrate that insurers in more-competitive markets can have a greater

\footnotetext{
${ }^{4}$ Note that we are focusing on how the level of competition, as measured by the number of competitors in the market, affects the decision to price discriminate. There is also a literature that discusses that price discrimination can lead to more-intense price competition (see Corts 1989; Shaffer and Zhang 1995). This is a different effect, although we will discuss this potential endogeneity when we present our empirical results.

${ }^{5}$ Similarly, Stole (1995), Desai (2001), and Rochet and Stole (2002) show that the quality distortion associated with price discrimination can diminish as the level of competition increases.
} 
incentive to screen between consumer types than insurers in less-competitive markets. $^{6}$

In the presence of fixed costs, increased competition can also lead to more price discrimination by triggering a prisoner's dilemma where each list pays the sunk costs required for price discrimination, but where all lists would be better off if no lists price discriminated. Such a situation could arise if consumers obtained similar value from each of the products offered by a given firm. ${ }^{7}$ In this case, a firm without much competition has low incentives to pay the fixed costs of offering more choices to consumers since any new products would simply cannibalize existing sales. However, when there is more competition, firms may now offer a larger menu of choices, despite some cannibalization, in order to attract consumers from competitors. Seim and Viard (2004) demonstrate that this prisoner's dilemma will persist for second-degree price discrimination when the cost of offering consumers more choices is not too expensive.

Because current theory offers conflicting predictions whether price discrimination will increase or decrease with higher competition, ${ }^{8}$ we treat the relationship between price discrimination and competition as an empirical question. Most of the literature examining this link has focused on the question of how competition affects the curvature of a pricing schedule (an inherently second-degree question). Examples include Stavins (2001), Busse and Rysman (2005), Miravete and Röller (2004) and Cohen and Kiser (2007). These studies all find that competition is associated with an increased curvature in the price schedule. $^{9}$

There are also a few papers that examine the link between competition and the similar topic of price dispersion. Borenstein and Rose (1994) find

\footnotetext{
${ }^{6}$ Another way to gain intuition about why competition can either increase or decrease the variance in consumers' willingness-to-pay is to note that when competitors enter into a market, theory dictates that any particular consumer's willingness-to-pay for the incumbent's product should decrease. However, this decrease can be either larger or smaller for customers that initially have a high willingness-to-pay relative to the size of the decrease among consumers that initially have a low willingness-to-pay. If the decrease is larger for consumers with low willingness-to-pay, the variance in the distribution of willingness-to-pay increases.

${ }^{7}$ While the example in this paragraph uses the language of second-degree price discrimination, similar logic applies for third-degree price discrimination. Instead of offering more menu choices, the firm would target prices for more groups of customers.

${ }^{8}$ In fact, Yang and Ye (2008) show that the relationship between competition and price discrimination need not be monotonic.

${ }^{9}$ While this seems to suggest that there is more price discrimination in more-competitive markets, deeper consideration reveals that it is often hard to tell whether increased curvature should be interpreted as more or less price discrimination. For example, Busse and Rysman's study of the yellow pages advertising market reveals that prices of large ads fall by a greater percentage than those of small ads under increased competition. However, it is unclear whether this should be viewed as increased quantity discounting (more price discrimination) or a move towards marginal cost pricing (less price discrimination). Because of this difficulty in interpretation of the results, these papers are careful not to draw conclusions about whether price discrimination increases with competition.
} 
that airline routes with greater competition exhibit a greater level of price dispersion. Similarly, Asplund et al. (2008) study the newspaper industry and find that newspapers in duopoly markets offer a discount to a greater fraction of their consumers than newspapers in monopoly markets. However, in recent work revisiting the airline results using newer panel data, Gerardi and Shapiro (2007) find the that price dispersion decreases with competition, and that the reduction is greater on routes where consumers have relatively heterogeneous elasticities of demand. Further, Chintagunta (2002) examines the effect of retail competition on optimal pricing in the analgesics (pain reliever) category and finds that competition leads to lower prices on Tylenol's price, while increasing the store-brand's price. This also implies that competition is reducing the amount of price dispersion in that category.

In contrast to these papers, we focus on how the level of competition affects the firm's decision whether to price discriminate along different dimensions, and if so, the number of options presented to consumers. Examining this decision of whether to price discriminate provides a direct way to measure whether the prevalence of price discrimination is higher or lower in competitive markets. While we provide fresh insights into both second and third degree price discrimination, we highlight that the empirical link between competition and third degree price discrimination has been particularly understudied.

The closest paper to ours is Seim and Viard (2004), which studies the US cellular telecommunications industry and examines how entry affects the number of pricing tariffs that incumbent firms offer, finding that increased competition leads to a proliferation of calling plans. Our paper differs in a number of important ways. First, we examine both second and third degree price discrimination, while Seim and Viard only examine second degree price discrimination. Further, the type of second degree price discrimination is different in the two papers. Seim and Viard examine second-degree price discrimination in the form of different tariff structures: some consumers may pay different prices, but all consumers who make a call are buying a good of the same quality. In contrast, the second-degree price discrimination that we examine is discrimination of the form of either quality discrimination or mixed bundling. ${ }^{10}$ Finally, only a fraction of the firms in our data engage in price discrimination along each of the different dimensions that we observe. Thus, we are able to examine how competition influences a firm's decision whether to price discriminate in a given dimension in addition to how competition affects the number of choices offered.

\footnotetext{
${ }^{10}$ The similarity to quality discrimination comes from the fact that offering more selective lists allows direct mailers to better target their advertising and should therefore be more valuable relative to the base list. For example, a mailer may be willing to pay more for names of more recent buyers or of buyers who have large purchase amounts, since the prospects may be more likely to respond to the mailer's offer or to spend more, conditional on responding. On the other hand, one could also view this as bundling: purchasing a base list could be viewed as buying, at a discount, the bundled product comprised of the names from each of the more selective lists.
} 
The remainder of this article proceeds as follows. In Section 2, we describe the mailing list industry and the data. We also describe our measures of price discrimination and competition. The results are discussed in Section 3. Section 4 summarizes and discusses the broader implications of our findings.

\section{Mailing lists}

\subsection{Industry capsule: the mailing list industry}

For over eighty years, businesses have been compiling and trading lists of customers, forming the core of an ever-expanding direct marketing industry. ${ }^{11}$ Marketers purchase these lists in order to contact potential customers by mail with information, advertisements, special offers, etc. regarding their products and services. In 1996, the last date for which the authors have been able to find such data, the mailing list industry had sales of roughly $\$ 1.7$ billion and over 31 billion names were exchanged (Borzekowski 1999).

Despite the importance of the direct mail industry, relatively little academic research has been conducted on the industry. Bult and Wansbeek (1995) demonstrates how to optimally target a direct mail campaign. Steenburgh et al. (2003) and Füsun and Ter Hofstede (2006) both discuss statistical issues with direct mail data. There has also been a series of papers that examine consumer response in the mail-order industry by examining the results of experiments run by an actual mail order catalog. Anderson and Simester (2004) and Simester et al. (2006) examine dynamic issues in mail-order catalogs, studying how current mailings affect future purchase behavior. Anderson and Simester (2008), Anderson et al. (2006) and Anderson et al. (2009b) all also use experiments from a mail-order catalog to examine how consumers respond to perceived unfair prices, stockouts, and return policies, respectively. Finally, Anderson et al. (2009a) consider the affect of tax policy on both consumer and firm behavior.

Second-degree price discrimination is implemented through the use of 'selects,' or subsets of the list. For example, if a mailing list offers a multi-buyer select then the marketer can choose either to rent names belonging to the base list, or to pay a premium and rent only names of consumers who made multiple purchases from the catalog that generated the mailing list. The most common forms of selects that we study include multi-buyer selects, gender selects, dollar selects, recency selects and inquirers-only selects. ${ }^{12}$

\footnotetext{
${ }^{11}$ See Burnett (1988) for history and details of the list industry.

${ }^{12} \mathrm{Almost}$ all lists offer geographic selects based upon the consumer's state or zip code. Since this information is part of the address itself, these selects can be offered with no additional investment by the list owner. Because they are almost universal, we do not include these in our analyses.
} 
Dollar selects are based upon the amount of money the customer has spent with the catalog, while gender selects allow marketers to send mailings to only men or only women who made purchases from the catalog. Recency selects are based upon the timing of the last purchase that the rented name made from the underlying catalog. The base list consists of the most recent sets of names from the catalog, but if a list owner offers a recency select then marketers can, at a discount, buy names of customers who made their purchase further in the past. Because the timing of recency selects vary across the different lists, we created a tag of 'Vintage Names Available' which we applied to all catalogs that offered names of consumers who had last made a purchase from their catalog more than 24 months prior. While the decision to offer vintage names is clearly a type of recency select, we include the vintage variable to set a uniform standard of quality degradation across the lists. Finally, inquirers-only selects provide names of people who have asked for a catalog but never made a purchase, and are also sold at a discount. ${ }^{13}$

List owners that offer dollar selects or recency selects also have to decide how many choices to offer. For instance, list owners can offer names of consumers who bought over $\$ 75$ worth of items from the catalog at a premium from the price for names off the base list. The same manager could instead choose to offer two different dollar select options: names of those who bought over $\$ 50$ worth of items at a low premium, or names of those who bought over $\$ 100$ worth of items at a high premium. Recency selects work very similarly; in addition to his or her base list, one list owner may choose to offer one recency select with names of consumers who made a purchase from the catalog within the last 6 months, while another owner may offer three selects; names of consumers who made a purchases in the last 3 months, the last 6 months or the last 12 months, with prices being lower for names of people who made purchases longer ago.

List owners can also engage in third-degree price discrimination. The most common form of third degree price discrimination involves offering a discount to fundraisers or not-for-profits. Roughly $45 \%$ of catalog lists offer this type of discount. These fundraiser discounts can be substantial and often involve the additional perk of not having to pay an additional premium for any requested selects. The other type of third degree price discrimination we examine is

\footnotetext{
${ }^{13}$ Offering additional selects is similar to expanding the number of products that are offered. As authors including Moorthy (1984) and Johnson and Myatt (2003) have noted, there exists a duality between some forms of second-degree price discrimination and product-line expansion. For example, the decision of how many package sizes to offer can be viewed as either a product line decision or as a price discrimination decision if the purpose of offering the different sizes is to extract consumer willingness-to-pay (Cohen 2008). However, Draganska and Jain (2006) demonstrate that not all product-line expansions constitute price discrimination. They find that in the yogurt industry, only vertically-differentiated product line variation can be used for price discrimination, while horizontal product-line expansion generally cannot. Thus, our paper can shed light on how the optimal product line differs with the level of competition to the extent that product lines are being chosen for the purpose of price discrimination.
} 
whether the mailing list owners charge a premium to marketers from businesses that compete directly against the underlying catalog; approximately $10 \%$ of lists have such a surcharge.

We note that list owners are represented by list managers who handle the sales and marketing of the owner's list. In 1997 there were 150 such managers who advised owners of the catalog lists. Most of these managed a relatively small number of lists-only 25 managed more than 10 lists. List managers generally receive a $10 \%$ commission, and work with the list owners to set prices and decide about the selects to be offered. As a result, we treat the decision to price discriminate as a profit-maximizing decision by well informed agents: even small list owners who rent their lists solely for some extra income will price strategically with the help of the list manager.

When a marketer rents a list from a list owner, the list owner sends the names directly to a third party printshop/mailing house that processes the mailing. If the mailer wishes to send out a second mailing to the same consumers then they must pay for the access to the mailing list twice. The use of the third party is one way to ensure that the mailers are not able to resell the mailing list. Additionally, list owners include a few fake addresses ("seeds") among the actual names, so they can confirm that their lists are being used only once and that mailings only include authorized materials. Preventing the resale of the access to the lists is what makes price discrimination possible.

The mailing list industry was not as technologically advanced in 1997 as some readers might anticipate. While the technology had advanced beyond the stage of storing data on physical cards, the 1997 technology primarily used magnetic tape to transfer data between the parties. Data files maintained by the list manager were often extracts of data used for the catalogs operations. To offer selects, these extracts needed to include the extra fields on which to separate the data. Thus, if a firm wanted to offer a gender select then the firm had to invest in extracting gender data from its main files. To offer very recent names the firm had to invest in technology to make rapid updating easy and efficient. The main point is that, counter to our intuition today, choosing to price discriminate did involve significant fixed-cost investments. ${ }^{14} \mathrm{By}$ 2002 these fixed costs had decreased, although the industry was still not near the forefront of technology. Note, though, that the marginal cost of price discriminating is zero once the fixed cost of price discriminating along a certain dimension has been made.

The degree to which marginal costs are truly zero is underscored by the fact that the mailer is charged for any additional costs besides the costs of the names themselves when purchasing names from a list owner. For example, these costs includes a fee for any media, such as magnetic tape, on which the names are delivered.

\footnotetext{
${ }^{14}$ For lists maintained on paper cards, an owner wishing to discriminate had to keep three sets of names: a master list with all of the names, a list with all of the names of the men, and a list with all of the names of the women. Such a division would be required for any select that the mailing list offered.
} 


\subsection{Data}

This paper focuses on catalog-based response lists, which include the names of people who have either ordered from, or in some cases inquired about, a mail-order catalog. The data consists of datacards for catalog-based consumer response lists as of June 1997 and May 2002. The sample restrictions imply that the names on each list are consumers (rather than businesses) who have inquired about or purchased from a given catalog. The data include every datacard in the database maintained by Marketing Information Network (mIn), a company that supplies this directory to market participants looking to rent a list. ${ }^{15}$ Mailers, or their marketing agents, pay for a subscription to the mIn directory service and are then able to search the database for lists to rent. ${ }^{16}$

Each datacard includes the catalog name and the quantity of names available (in discrete categories) along with the price per thousand names. The datacard also lists the availability, name counts, and prices for all selects.

Tables 1 and 2 describe the data. In 1997, there were roughly 1,800 datacards for lists distilled from mail-order catalogs. From this, we excluded international lists, as well as lists that were no longer adding new names. Also, some firms used multiple datacards to represent names from the same list. In these cases, we aggregated all datacards from the same base list into a single observation. This leaves a sample of 1,209 lists in 1997, and 1,405 lists in 2002. These values, however, mask substantial entry and exit: of the original 1,200 lists available in the first period, roughly 500 exited by 2002. Most lists are relatively small, containing under 100,000 names, although a few have over 1 million names.

Tables 1 and 2 also show the fraction of lists offering the different selects in each year. Gender selects are offered by between just over half to two-thirds of the lists, depending on the sample year. Across the two years, dollar selects are offered by about $40 \%$ of lists, while recency selects are offered by about $67 \%$ of lists. Multi-buyer selects are much less common: only about $15 \%$ of lists offer a multi-buyer select. The fraction of lists offering vintage and inquirers only names both drop from about $40 \%$ of lists in 1997 to about $33 \%$ of lists in 2002. The lines labeled "Differential Rates" in these tables show the fraction of lists engaging in third-degree price discrimination. Approximately $45 \%$ of lists offered special reduced rates to fundraisers or not-for-profit organizations, while a much smaller number charge higher prices to firms that compete in the same underlying business.

\footnotetext{
${ }^{15}$ While we have the universe of mailing lists that are offered by firms, not every firm rents their names. For example, some firms might be worried that they will lose customers who resent their private information being sold. We also do not observe catalog owners that do not make their list available for sale, but do engage in trading of names directly with other selected mailing lists. In Section 3.3.1, we find a high correlation between the number of firms in an industry and the number of mailing lists in that industry.

${ }^{16}$ One other firm, SRDS, offers a similar directory. However, only mIn offered an online database at the time of the first sample.
} 
Table 1 Summary statistics 1997

\begin{tabular}{|c|c|c|c|c|c|}
\hline Variable & Mean & Std. dev. & Min & Max & $\mathrm{N}$ \\
\hline \multicolumn{6}{|l|}{ List size } \\
\hline 0-49,999 Names & 0.40 & 0.49 & 0 & 1 & 1209 \\
\hline 50,000-99,999 Names & 0.23 & 0.42 & 0 & 1 & 1209 \\
\hline $100,000-199,999$ Names & 0.15 & 0.36 & 0 & 1 & 1209 \\
\hline 200,000-299,999 Names & 0.07 & 0.25 & 0 & 1 & 1209 \\
\hline 300,000-399,999 Names & 0.03 & 0.18 & 0 & 1 & 1209 \\
\hline 400,000-499,999 Names & 0.03 & 0.17 & 0 & 1 & 1209 \\
\hline 500,000-999,999 Names & 0.05 & 0.21 & 0 & 1 & 1209 \\
\hline $1,000,000+$ Names & 0.04 & 0.20 & 0 & 1 & 1209 \\
\hline \multicolumn{6}{|l|}{ Selects available } \\
\hline Gender select available & 0.55 & 0.50 & 0 & 1 & 1209 \\
\hline Dollar select available & 0.38 & 0.49 & 0 & 1 & 1209 \\
\hline Recency select available & 0.68 & 0.47 & 0 & 1 & 1209 \\
\hline Multi-buyers available & 0.15 & 0.36 & 0 & 1 & 1209 \\
\hline Inquirers available & 0.41 & 0.49 & 0 & 1 & 1209 \\
\hline Vintage names available & 0.37 & 0.48 & 0 & 1 & 1209 \\
\hline 2nd degree count & 2.17 & 1.34 & 0 & 5 & 1209 \\
\hline \multicolumn{6}{|l|}{ Select counts } \\
\hline Dollar select count & 2.83 & 1.18 & 1 & 7 & 460 \\
\hline Recency select count & 2.35 & 1.10 & 1 & 7 & 824 \\
\hline \multicolumn{6}{|l|}{ Differential rates } \\
\hline Fundraiser rate available & 0.43 & 0.49 & 0 & 1 & 1209 \\
\hline Competitor rate available & 0.09 & 0.29 & 0 & 1 & 1209 \\
\hline 3rd degree count & 0.52 & 0.59 & 0 & 2 & 1209 \\
\hline \multicolumn{6}{|l|}{ Competition measures } \\
\hline CompMatch & 74.80 & 44.86 & 2.21 & 166.79 & 1209 \\
\hline CompAve & 120.12 & 71.83 & 4 & 281 & 1209 \\
\hline CompCos & 108.49 & 64.25 & 3.12 & 257.1 & 1209 \\
\hline \multicolumn{6}{|l|}{ Control variables } \\
\hline Apparel indicator & 0.23 & 0.42 & 0 & 1 & 1209 \\
\hline Mkt size: Dollar (\$bil) & 63.05 & 88.77 & 2.25 & 560.30 & 1094 \\
\hline
\end{tabular}

Table 3 presents the correlations between the different price discrimination variables. In general, the correlations tend to be positive, suggesting that lists that price discriminate tend do so in a number of ways. However, the correlations are generally low, allowing us to treat each pricing decision as a separate test of the link between competition and price discrimination.

\subsection{Measures of competition}

Our competition measures are derived from the 47 different categories into which mIn classifies lists. ${ }^{17}$ Most of the lists are classified into one or two

\footnotetext{
${ }^{17}$ The categories used are Animals/Pets/Wildlife, Apparel, Areas Of Interest, Arts Cultural/ Musical, Attendees, Beauty \& Cosmetics, Boats/Boating, Books, Children, Children's Apparel, Children's Books/Pubs, Children's Merchandise, Collectibles, Computers, Diet \& Fitness, Electronics, Environment, Fishing, Food/Kitchen Equipment, Furniture, Games/Contests/Puzzles, Gardening/Horticulture, General Merchandise, Gifts, GunsWeapons, Health, History, Hobbies Or Crafts, Home Decor/Accessories, Home Improvement, Hunting, Jewelry, Leisure/Recreation, Lotteries/Gambling, Men's Publications/Books, Motor Vehicles, Music, Photography, Record/ Cassette/CD, Sexually Oriented, Sports, Sports Merchandise, Tools/Equipment, Travel, Video Tapes, Women's Publications/Books, Woodworking.
} 
Table 2 Summary statistics 2002

\begin{tabular}{|c|c|c|c|c|c|}
\hline Variable & Mean & Std. dev. & Min & Max & $\mathrm{N}$ \\
\hline \multicolumn{6}{|l|}{ List size } \\
\hline 0-49,999 Names & 0.37 & 0.48 & 0 & 1 & 1405 \\
\hline 50,000-99,999 Names & 0.21 & 0.41 & 0 & 1 & 1405 \\
\hline $100,000-199,999$ Names & 0.17 & 0.37 & 0 & 1 & 1405 \\
\hline $200,000-299,999$ Names & 0.08 & 0.27 & 0 & 1 & 1405 \\
\hline 300,000-399,999 Names & 0.04 & 0.20 & 0 & 1 & 1405 \\
\hline $400,000-499,999$ Names & 0.03 & 0.16 & 0 & 1 & 1405 \\
\hline $500,000-999,999$ Names & 0.05 & 0.22 & 0 & 1 & 1405 \\
\hline $1,000,000+$ Names & 0.05 & 0.23 & 0 & 1 & 1405 \\
\hline \multicolumn{6}{|l|}{ Selects available } \\
\hline Gender select available & 0.67 & 0.47 & 0 & 1 & 1405 \\
\hline Dollar select available & 0.40 & 0.49 & 0 & 1 & 1405 \\
\hline Recency select available & 0.66 & 0.47 & 0 & 1 & 1405 \\
\hline Multi-buyers available & 0.16 & 0.37 & 0 & 1 & 1405 \\
\hline Inquirers available & 0.34 & 0.47 & 0 & 1 & 1405 \\
\hline Vintage names available & 0.33 & 0.47 & 0 & 1 & 1405 \\
\hline 2nd degree count & 2.24 & 1.29 & 0 & 5 & 1405 \\
\hline \multicolumn{6}{|l|}{ Select counts } \\
\hline Dollar select count & 2.89 & 1.18 & 1 & 8 & 564 \\
\hline Recency select count & 2.41 & 1.20 & 1 & 12 & 933 \\
\hline \multicolumn{6}{|l|}{ Differential rates } \\
\hline Fundraiser rate available & 0.47 & 0.50 & 0 & 1 & 1405 \\
\hline Competitor rate available & 0.13 & 0.34 & 0 & 1 & 1405 \\
\hline 3rd degree count & 0.60 & 0.66 & 0 & 2 & 1405 \\
\hline \multicolumn{6}{|l|}{ Competition measures } \\
\hline CompMatch & 90.26 & 50.55 & 1.38 & 191.01 & 1405 \\
\hline CompAve & 155.34 & 86.07 & 4 & 358 & 1405 \\
\hline CompCos & 138.85 & 77.69 & 2.01 & 340.24 & 1405 \\
\hline \multicolumn{6}{|l|}{ Control variables } \\
\hline Apparel indicator & 0.26 & 0.44 & 0 & 1 & 1405 \\
\hline Mkt size: Dollar (\$bil) & 91.50 & 128.16 & 3.11 & 725.59 & 1268 \\
\hline
\end{tabular}

categories (see Fig. 1) and a careful inspection of the data suggests that cases where the lists are classified in multiple categories are legitimate.

Using this classification, our basic approach to calculating competition measures is to add the number of lists that are classified in the same categories as the given list. However, this approach is complicated by the fact that lists often only partially overlap in their industry classifications. In these cases, we use measures where lists that partially overlap in their classifications count as providing some competition, but less than those lists that have exact matches. Note that this is justified not only in terms of the underlying characteristics of the list, but also in the institutional way that many marketers use to decide which mailing list to purchase: Using the mIn software, mailers can search by inputting industry codes and then choosing lists from the results of those queries.

We use three different measures of competition in order to ensure that the exact way that we calculate our competition measure is not driving our results. All three measures are based on the same principle; lists that have no overlapping classification codes are given a competitor weight of zero, lists that have exactly the same classification codes are given a weight of one, and lists 


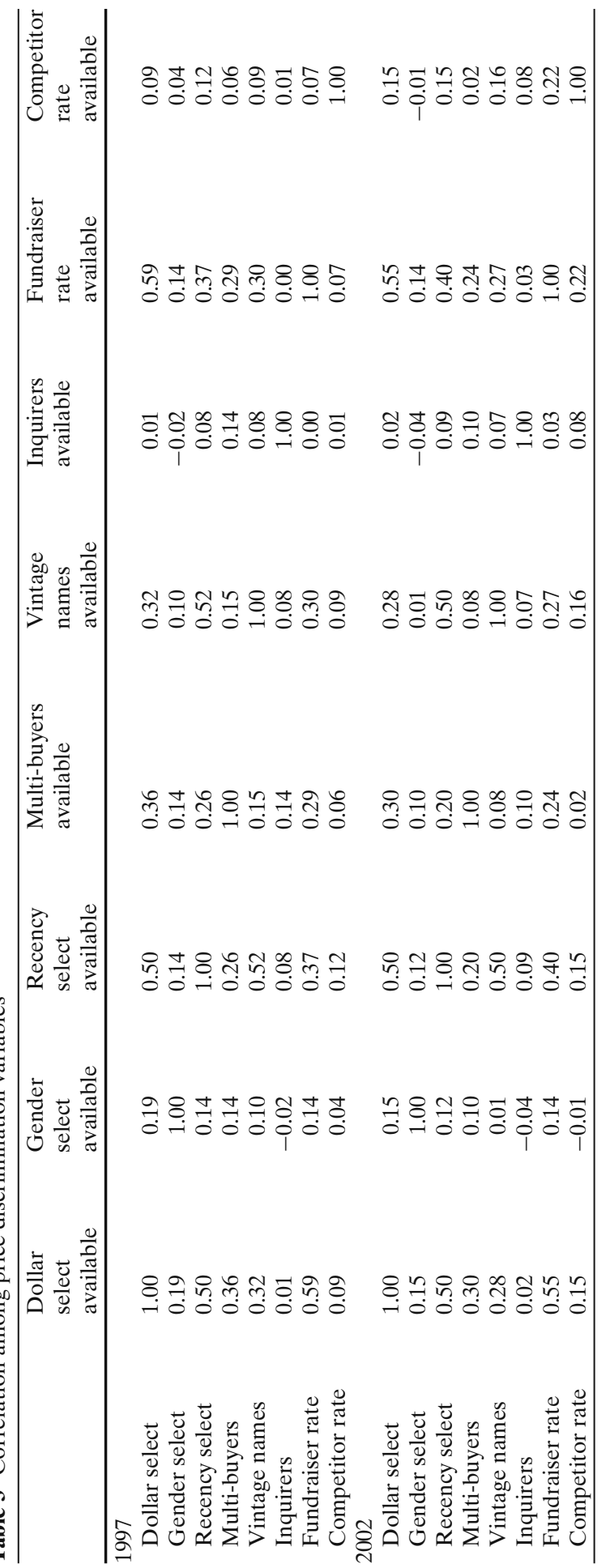



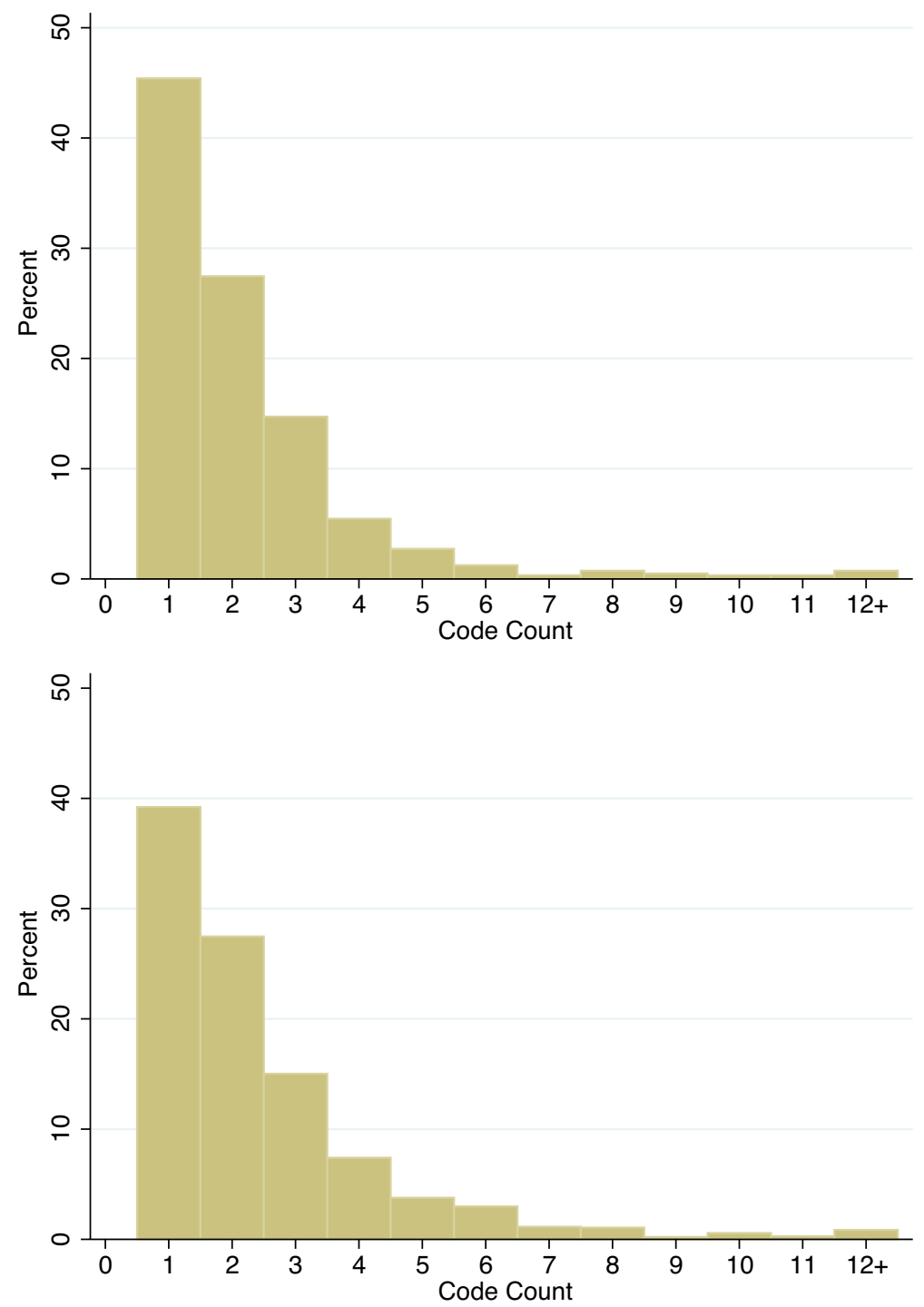

Fig. 1 Distribution of number of codes describing lists-1997, 2002

that partially overlap are given a weight between zero and one. The competition measure is then the sum of these weights. The variation in our three competition measures lies in how they calculate the weight for partiallyoverlapping lists. ${ }^{18}$

\footnotetext{
${ }^{18}$ These measures are related to distance metrics frequently used in cluster analysis involving binary variables. See Anderberg (1973) for a discussion of these metrics. 
Our main competition measure, CompMatch, is constructed by calculating pairwise the fraction of codes present for two lists that are common between them, and then summing this value for all pairs of lists. Specifically,

$$
\text { CompMatch }_{i}=\sum_{\text {lists } j \neq i} \frac{\text { Number of codes listed by both } i \text { and } j}{\text { Number of codes listed by } i \text { or } j}
$$

CompMatch has the advantage of being intuitive, symmetric and utilizing the information of non-matching codes from both lists.

We also examine whether we get similar results when we use two other measures of competition; CompAve and CompCos. CompAve is calculated as:

$$
\text { CompAve }_{i}=\sum_{\text {lists } j \neq i} \frac{\text { Number of codes listed by both } i \text { and } j}{\text { Number of codes listed by list } i}
$$

CompAve is similar to CompMatch, except that the denominator includes only those codes on the list for which competition is being calculated. This measure is a bit awkward because it is asymmetric and because it throws away some information about the degree of list similarity. However, it is the average number of competitors that will appear in any query that would include the featured list, so it has some intuitive appeal.

To calculate the last measure, we first create a vector of ones and zeros to indicate whether a particular list is classified as being in each industry. CompCos is then constructed by calculating the cosine of the angle formed between the code vector and a similar vector for each other list and then summing over all lists. The cosine between two lists with exactly the same industry codes is one while the cosine for lists with no overlap is zero, and, because all vectors are non-negative, any partial overlap will lead to a cosine between zero and one. More formally,

$$
\begin{aligned}
& \operatorname{CompCos}_{i} \\
& =\sum_{\text {lists } j \neq i} \cos (i, j) \\
& =\sum_{\text {lists } j \neq i} \frac{\text { Number of codes listed by both } i \text { and } j}{\sqrt{\text { Number of codes listed by list } i * \text { Number of codes listed by list } j}}
\end{aligned}
$$

The summary statistics for these competition variables appear in Table 1 and Table 2. Histograms of CompMatch appear in Fig. 2 to give the reader a broader understanding of the distribution of competition. Table 4 presents the correlations between these different measures. The correlations between these measures are high, largely because of the number of lists that are classified in only one or two industries.

CompMatch and the other competition measures attempt to capture the similarity between the different lists by accounting for the degree to which the 

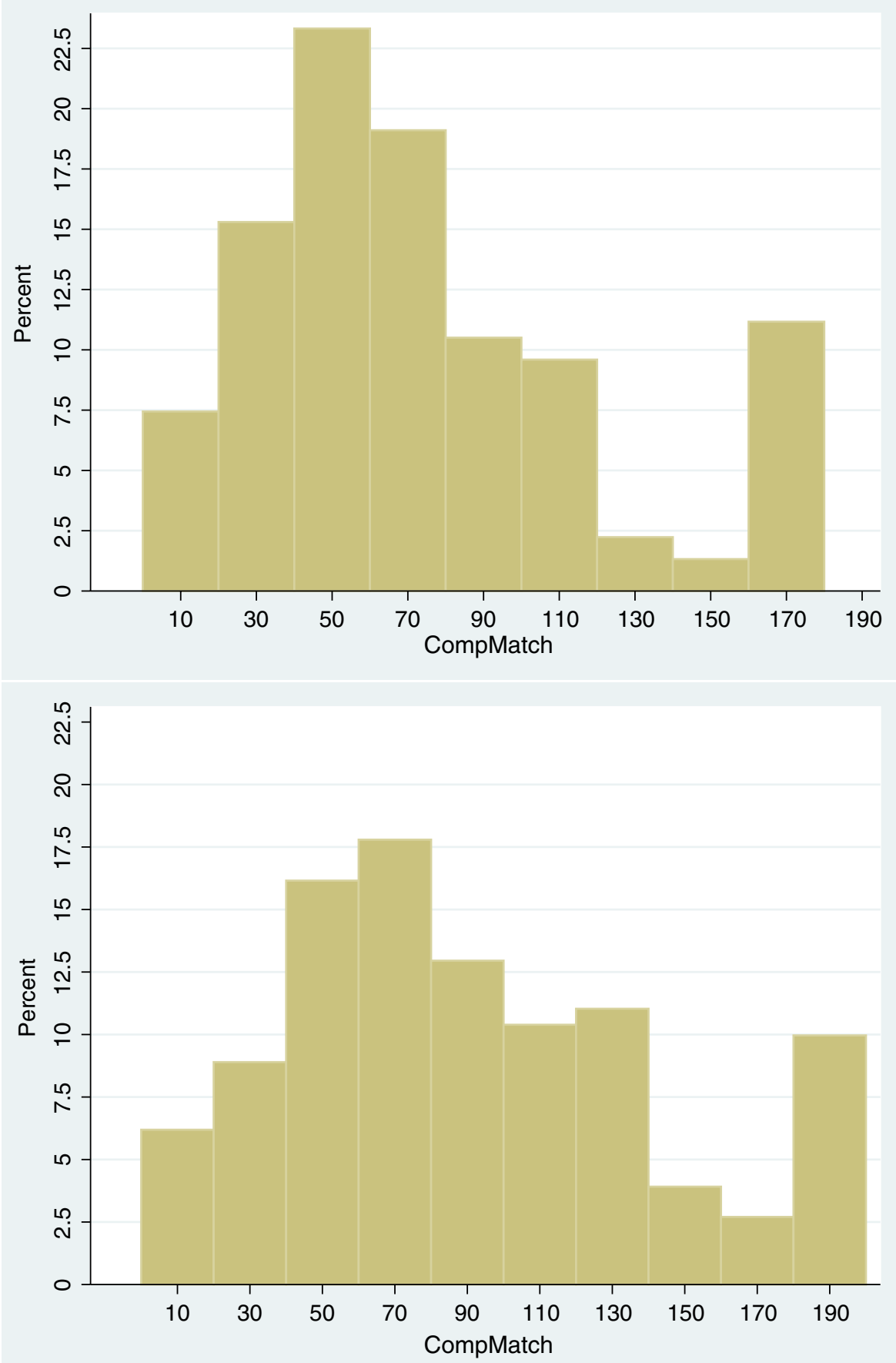

Fig. 2 Distribution of competition measure-CompMatch-1997, 2002 
Table 4 Correlation among competition measures

\begin{tabular}{llll}
\hline & CompMatch & CompAve & CompCos \\
\hline 1997 & & & \\
CompMatch & \multirow{2}{*}{1.00} & 0.95 & 0.94 \\
CompAve & & 1.00 & 0.85 \\
CompCos & & & 1.00 \\
2002 & & \\
CompMatch & \multirow{2}{*}{00} & 0.93 & 0.95 \\
CompAve & & 1.00 & 0.80 \\
CompCos & & & 1.00 \\
\hline
\end{tabular}

lists are classified in the same way. However, our data do not allow us to control for the degree of heterogeneity among the lists within a particular code. One consequence of not being able to fully capture product differentiation is that our measures of competition appear to be high. For example, while many lists have few competitors, the mean number of competitors for each list in 2002 was near 90. We do not interpret this number as representing perfect competition: Rather, our assumption is that these measures are correlated enough, or even proportional, to the 'true' amount of competition that these firms face given the unobserved differentiation.

However, to control for some of the unobserved heterogeneity, we also conduct an additional analysis using just lists with over 100,000 names. This is a reasonable approach to take if these lists form their own 'markets,' different from the smaller, more specialized lists. In these analyses, the primary competition measure is recalculated assuming that only the larger lists compete with each other, and restricting the regression sample to the larger lists as well. The subsample includes about $40 \%$ of the original sample. Here, the mean number of competitors in 2002 drops to 50 . As we report later, the main results generally become stronger when we do this.

Finally, all of the results presented in this paper focus on the impact of the natural log of competition. We focus on the log of competition because, consistent with many theories of competition, we expect that the impact of each marginal competitor becomes smaller as the total number of competitors increases. That is, we expect that the differences between having 10 vs. 20 competitors is substantially larger than the difference between having 130 vs. 140 competitors. We have also confirmed that this functional form is reasonable by using other flexible forms, such as including linear and squared terms.

\subsection{Other variables}

In addition to the competition measure, the estimation controls for the size of each mailing list. There are three reasons we include the size of the list in the regression. First, smaller lists may find it harder to recover any fixed costs that are necessary to engage in price discrimination because their revenues will generally be lower. ${ }^{19}$ Second, smaller lists may already be focused on a

\footnotetext{
${ }^{19}$ These fixed costs are discussed earlier in Section 2.1.
} 
more-targeted segment, which in turn leads to the selects being less valuable. ${ }^{20}$ Finally, there is an inherent tradeoff when offering selects: While offering a select can increase the total number of customers that rent the list and increase the price per name, some direct mailers who choose a select may have chosen to rent the entire base list if the select were not available. Generally, prices observed in the data dictate that revenues from selling an entire list are greater than revenues from selling an entire select. Smaller lists will find that the probability of selling their full list are higher than they are for larger lists, where orders are constrained by the size of the marketer's budget or campaign. ${ }^{21}$

The focus of this study is on the relationship between market structure and the propensity to engage in various forms of price discrimination. To control for the possibility that the decision to price discriminate depends on the size of demand for a mailing list instead of the number of competitors, the empirical specifications include measures of market size. We do not observe direct quantity data, nor do we know how many mailers may be interested in a given list. Instead we proxy market size with the average total sales in the industries with the NAICS codes that best match the mIn categories. These data are collected from the Economic Census. When mailing lists classify themselves in multiple industries, we average over all of the mIn categories for which we were able to match NAICS codes. Because the industry size information is missing for some observations, the number of observations used in the estimation is reduced from 1,209 $(1,405)$ to 1,094 $(1,268)$ in $1997(2002)$.

\section{Results}

Our findings broadly demonstrate that mailing list owners in more competitive industries are more likely to price discriminate along more dimensions. We find that this is true for both second- and third-degree price discrimination. Further, among those mailing lists that choose to implement second-degree price discrimination, those in more competitive markets tend to offer menus with more options than those in less competitive markets.

\subsection{Second-degree price discrimination}

We examine the link between competition and second-degree price discrimination by estimating the decision to use each of the different types of price discrimination strategies (selects) as separate probit regressions. ${ }^{22} \mathrm{We}$ also run

\footnotetext{
${ }^{20}$ We thank an anonymous referee for pointing out this tradeoff.

${ }^{21}$ We will find that lists with less than 100,000 names are less likely to conduct price discrimination than lists with over 100,000 names. However, our main results about the impact of competition become even stronger when we run this analysis on only lists with over 100,000 names and thus avoid these issues.

${ }^{22}$ Jointly estimating the probits as a multivariate system yields similar results.
} 
Poisson regressions on the numbers of selects each firm offers as well as the numbers of dollar-select and recency-select cutoffs offered by the firms. The independent variable of interest in all our specifications is the competition measure. We initially assume that the level of competition is exogenous and justify this assumption. However, we also present additional analyses using instrumental variables and difference-in-difference specifications, in Section 3.3, which yield equivalent results.

Table 5 presents results from 1997, while Table 6 presents results from 2002. The coefficients on competition are positive across all specifications, and the coefficients are also statistically significant at the $10 \%$ level, except for in the case of gender select availability and inquirers only availability.

The positive, statistically significant coefficients on competition demonstrate that mailing lists in markets with high levels of competition are more likely to exhibit second-degree price discrimination. The first few columns-those for dollar selects, gender selects and multi-buyer selects-can be interpreted as examples of offering products of higher quality in order to price discriminate. The vintage name and inquirers only selects, on the other hand, are examples of quality degradation-deliberately offering a degraded quality product in order to siphon off the low valuation buyers.

To gauge the approximate magnitude of the effects, the first line of each panel in Table 10 reports the increase in the probability of price discriminating that would be associated with moving from the 10th percentile of the competition measure to the 90th percentile, holding the other variables fixed at their respective means. The largest effect is for dollar selects, where the increase in competition is associated with a $27 \%$ (35\%) increase in the probability of price discriminating in 1997 (2002). In the data, roughly 40\% of lists offer this select, indicating that competition seems to have a substantial effect. Similarly, moving between these two levels of competition is associated with a $19 \%$ increase in the probability of offering vintage names, compared to the $36 \%$ of lists that offer the select in 1997. The magnitudes of the effects for recency and multi-buyer selects are smaller, although the $7 \%$ change in probability associated with the multi-buyer select may seem more significant given that only $16 \%$ of all lists offer a multi-buyer select.

We also show that the number of selects offered by firms increases with increased competition. To do this, we sum the number of selects that the firm offered among the dollar, gender, multi-buyer, recency and inquirers only select. Column 7 in Tables 5 and 6 report the result of Poisson regressions on the number of selects offered by the mailing list on competition and other variables. Note that the dependent variable can only take on values between 0 and 5; we omit vintage selects here since they themselves are a derivative of recency selects. These results confirm the findings from the probits of the individual selects: greater competition is associated with offering more selects. The magnitude of the effect is shown in Column 7 in Table 10. The difference in the expected number of second degree selects offered at the 10th and 90th percentiles of competition is .436 in 1997 , an increase of roughly $20 \%$ given the mean of 2.17 selects in the data. 


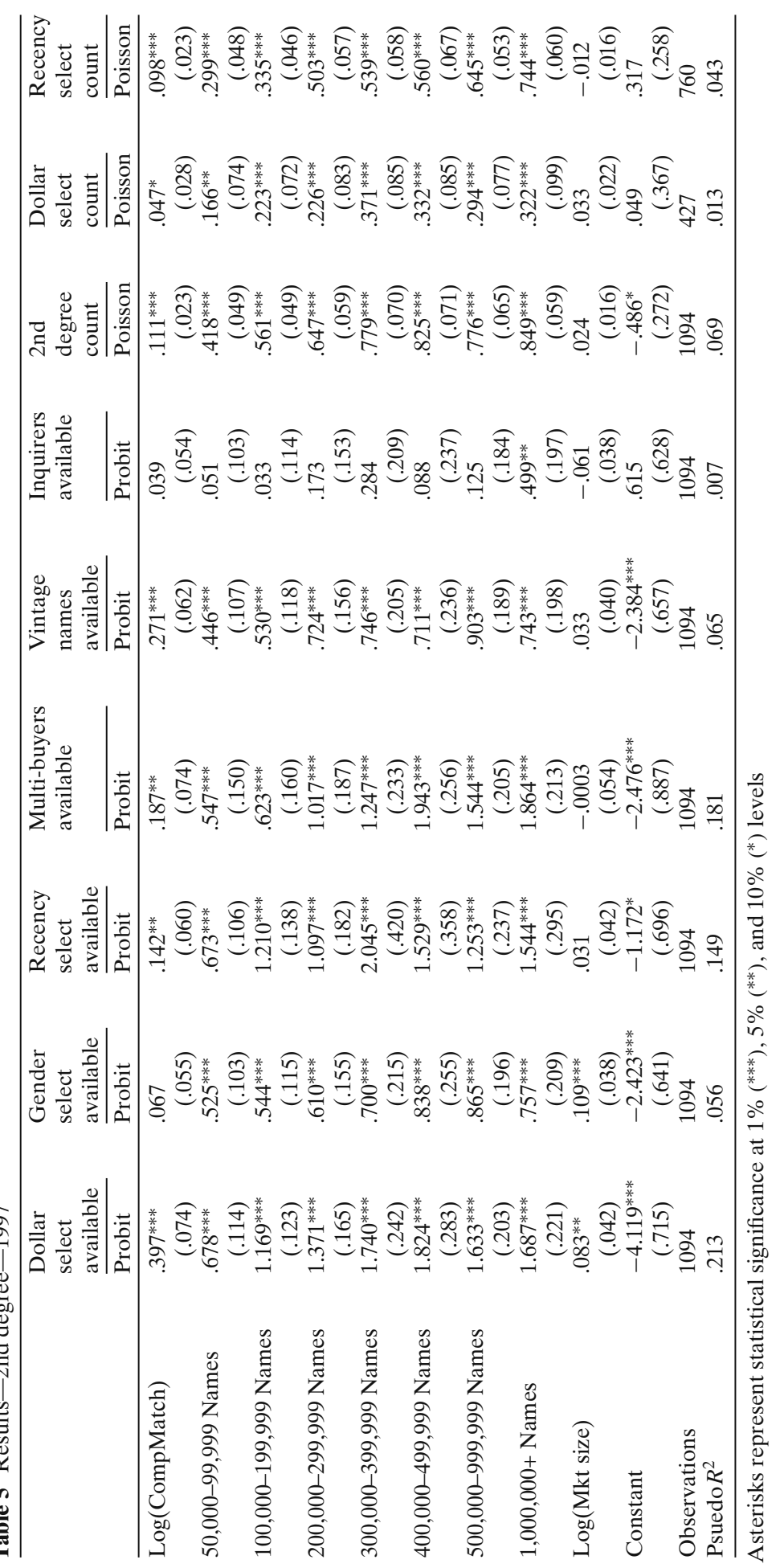




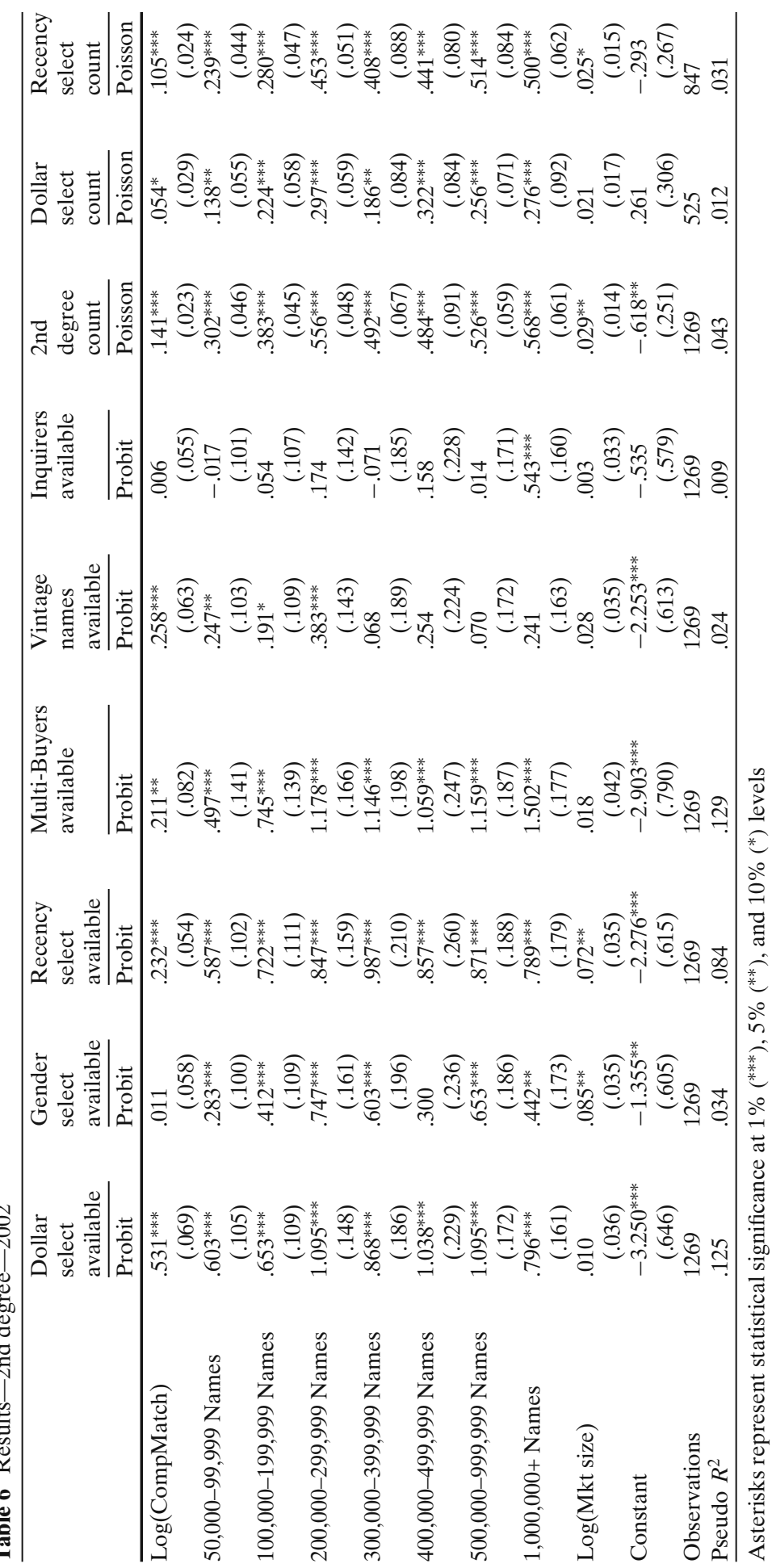


A common managerial practice can form the mechanism for this link between competition and offering more selects. Anecdotally, list managers advise lists that have low demand to increase the number of selects that they offer. If demand for lists is lower in more-competitive markets then this would create a managerial mechanism linking competition to the offering of selects. ${ }^{23}$

List owners offering dollar and recency selects also need to decide how many different dollar amounts or time horizon cutoffs they should offer. We sum the number of dollar selects or recency selects offered among those list owners who price discriminate and regress these counts on our competition measure. ${ }^{24}$ The results of these regressions are reported in columns 8 and 9 of Tables 5 and 6 . The coefficients on competition are positive and significant, indicating that greater competition is correlated with a greater partition of the product space. The two columns for counts in Table 10 show the difference in the expected number of dollar and recency selects offered at the 10th and 90th percentiles of competition, evaluating all other variables at their respective means. The change of roughly 0.23 dollar select counts represents an increase of $8 \%$ relative to the mean of roughly 2.8 in the sample. The results for recency are larger: the change of 0.4 recency counts represents an increase of $17 \%$ relative to a mean of 2.4 .

In addition to demonstrating a link between competition and price discrimination, the results also show that owners of large mailing lists are more likely to offer each of the selects we examine than owners of small mailing lists. To see this note that, except in the case of inquirers, lists with over 50,000 names on them are always statistically more likely to price discriminate than those lists with less than 50,000 names. It is also true that lists with over 100,000 names are more likely to price discriminate than lists with between 50,000 and 100,000 names, although the statistical significance and uniformity of this result is smaller. However, once lists are large enough — perhaps 200,000 names-it appears that additional names no longer factor into the decision to price discriminate. There is also evidence that larger lists offer menus with more choices to consumers. These results are consistent with the hypotheses advanced in Section 2.4. In Section 3.4 we will demonstrate that our results still hold when we limit our analysis to only larger mailing lists.

\subsection{Third-degree price discrimination}

We examine the link between competition and third-degree price discrimination by considering two types of third-degree price discrimination observed in the data: fundraiser rates and competitor rates. Table 7 reveals that greater competition is associated with a greater propensity to implement third-degree price discrimination in both years. Columns 1 and 2 (4 and 5 for 2002) report

\footnotetext{
${ }^{23}$ We thank an anonymous referee for bringing this practice to our attention.

${ }^{24}$ Similar results are obtained when the observations where these selects are not offered are included in the regressions.
} 


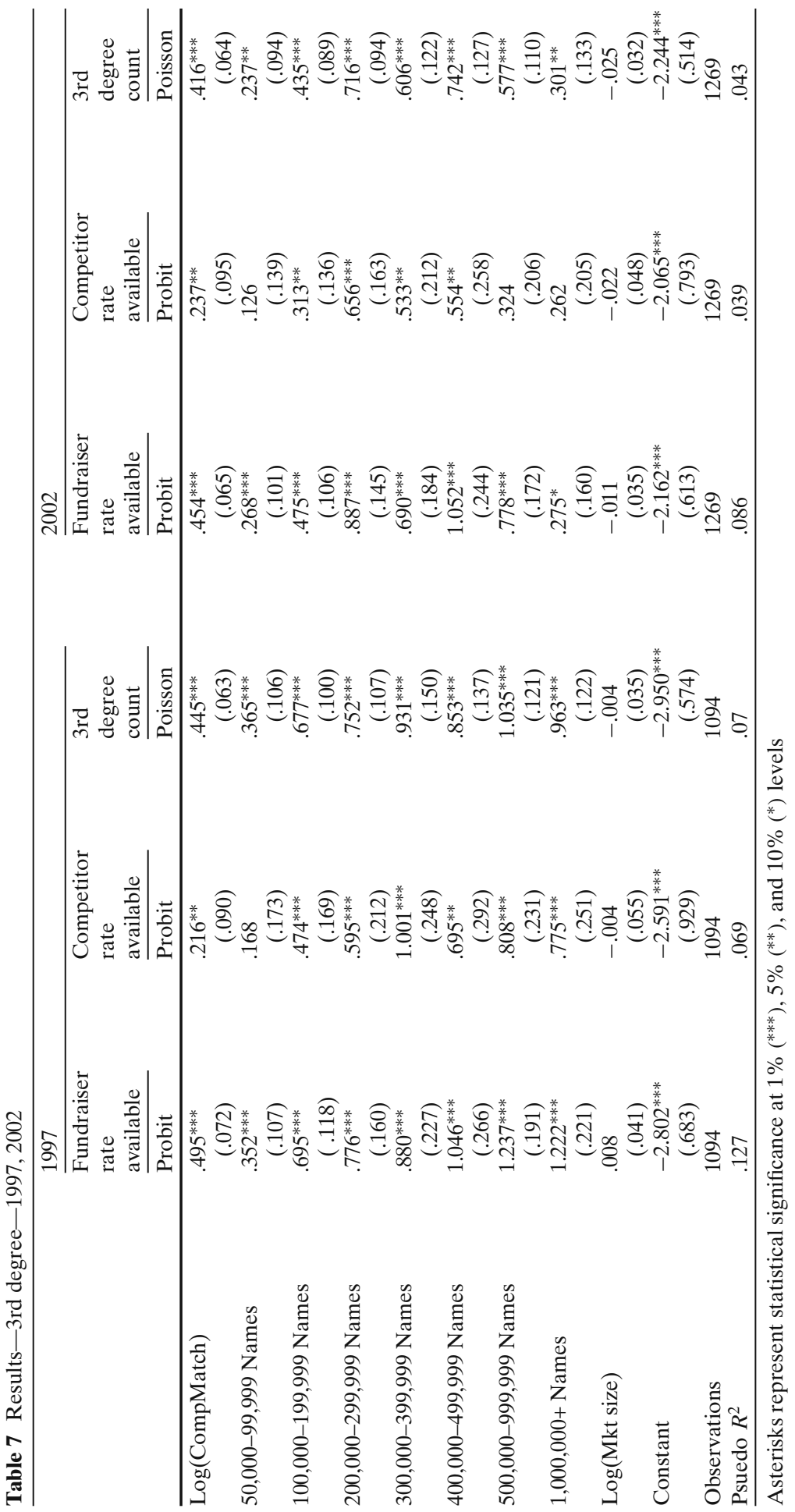


the results of probit analysis where the dependent variable is whether the firm gives a fundraiser discount or charges a competitor surcharge. The coefficients on competition are positive and significant. The third and sixth columns of Table 7 reports the results of a Poisson regression. The dependent variable is 0 if the firm has no separate pricing for fundraisers or direct competitors, 1 if the firm has a special rate for fundraisers or direct competitors but not both, and 2 if the firm has special rates for both groups. These regressions also show that firms in more-competitive markets offer more types of third-degree price discrimination. ${ }^{25}$

Table 10 shows that the changes in the probability of offering a fundraiser rate corresponding to the difference between the 90th and 10th percentiles of the competition measures is 36\% (31\%) in 1997 (2002). This probability is only $6 \%(8 \%)$ for charging competitor rates, although only $9 \%(13 \%)$ of all lists have a competitor surcharge in 1997 (2002).

Our findings that competition leads to more third-degree price discrimination is especially significant given the lack of a significant empirical literature linking third-degree price discrimination with competition. As we noted before, the previous empirical literature on the topic has generally focused on second-degree price discrimination except for the somewhat related paper of Asplund et al. (2008). The fact that we get similar results for second and third degree price discrimination also suggests that the result that greater competition tends to lead to price discrimination is fairly broad. In the conclusion of this paper, we speculate on which theoretical reason is driving our results. One reason that is consistent with our results for both the second- and third-degree price discrimination is that firms in more-competitive industries are more likely to use price discrimination to charge a high price to those customers who are unwilling to switch between competitors but a low price to those customers who are willing to consider competing products.

We also still find that larger lists are more likely to third degree price discriminate than smaller lists. This result is again consistent with small lists having a hard time recouping their fixed costs.

\subsection{The exogeneity of competition}

Our results above rely on the exogeneity of our competition measures. For this industry segment-mailing lists derived from catalogs—-the list itself is a

\footnotetext{
${ }^{25}$ It is possible that increased competition is associated with the presence of closer substitutes to the average list. Some readers and a referee have noted that if this is the case, the direct competitor surcharge may reflect the higher opportunity costs of renting a list. However, the list owner gets to decide who they view as their direct competitors-there is no fixed level of substitution that defines what it means to be competitors. Further, if there are low levels of competition it seems likely that a consumer who buys from a competing catalog may be displacing a purchase from the firm's catalog, but if there are many competitors there is a high probability that a purchase from one competitor is instead crowding out purchases from one of the many other competitors. This effect makes our result that increased competition leads to an increased probability of a competitive surcharges even more surprising. Note that this discussion does not apply to the fundraiser discount effects.
} 
byproduct of the list owner's primary business, namely selling merchandise. As such, firms' entry decisions, and by extension our competition measures, are likely to be exogenous in the analysis of the decision to price discriminate. ${ }^{26}$

However, it is theoretically possible that one firm's decision to price discriminate could affect another firm's decision to sell their mailing list, which would also lead to an endogeneity issue with the competition measure. As Shaffer and Zhang (1995) and Corts (1989) demonstrate, the presence of price competition can diminish the margins firms earn, and this smaller reward for selling their mailing list could prevent some firms from paying the fixed costs of offering their mailing lists for sale. It is also possible that common factors in an industry lead to both increased competition and an increased value of selects.

We address these potential concerns about endogeneity through the use of instrumental variables and difference-in-difference analyses. In both cases, the results discussed in Sections 3.1 and 3.2 continue to hold. In addition, the size of the impact of competition on price discrimination is unchanged under each of these robustness checks, further suggesting that the level of competition is exogenous to the decision to price discriminate.

\subsubsection{Instrumental variables probit analysis}

We address the concern that the decision to price discriminate might affect the level of competition the company faces through instrumental variables probit analysis. While we do not have any obvious candidates for instruments for the 1997 data, we can construct an instrument for competition for those mailing lists that entered after 1997 but before 2002. For these observations, which were present in 2002 but not in 1997, we use the competition measure that a list with the same industry codes would have faced if it had sold its mailing list in 1997. The correlation in the competition measures in 1997 vs. 2002 is $90 \%$, so this instrument has a high correlation with the variable we are trying to instrument for. However, there is no way for the decisions of these mailing lists to price discriminate to affect what the competition measures would have been before they entered the market.

Table 8 reports the instrumental variables probit results. The first 6 columns report the results for the availability of each of the 2 nd degree selects, while columns 8 and 9 report the results for the availability of the 3 rd degree selects. Columns 7 and 10 report the results of two-stage least squares regressions of the number of selects offered (0-5, and not counting the vintage select for the reasons explained above) or the number of 3rd degree price discrimination groups targeted $(0-2$, depending on whether they price fundraiser discounts and/or competitor surcharges).

\footnotetext{
${ }^{26}$ Indeed, the correlation between our measure of competition and the number of establishments for matching NAICS codes is 0.67 . In considering how high this correlation is, note that the number of establishments for each NAICS code includes businesses that are not running catalogs as well as those that are.
} 


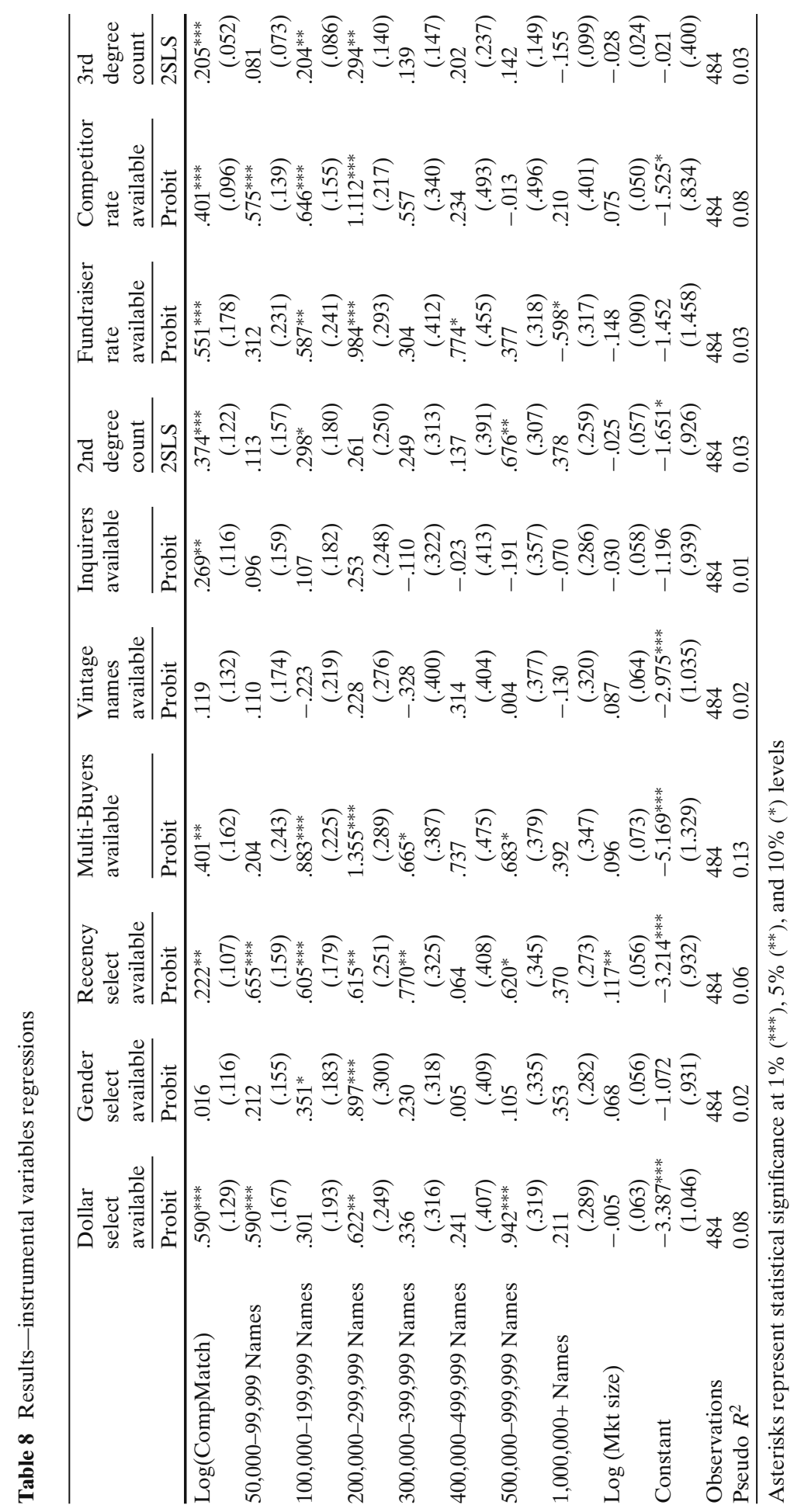


Examining this table, we find that the results are mostly unchanged. All of the coefficients on competition are positive. The only qualitative changes are that the coefficient for inquirers only becomes larger and statistically significant while the coefficient for vintage select availability is smaller and insignificant, due in part to a larger standard error. Except for the case of inquirers only selects, the coefficients from the probits where we assume that competition was exogenous fall within the $95 \%$ confidence interval for the instrumental variable probit analysis, suggesting that the assumption that firms' entry decision in this industry is not affected by the decisions of other firms to price discriminate is reasonable for this industry. ${ }^{27}$

\subsubsection{Difference-in-difference analysis}

There may be a simultaneity concern in addition to the endogeneity issue addressed above. It is conceivable that there is more heterogeneity in preferences in some industries than in others, and that this increased heterogeneity in preferences leads to both increased competition and increased value of selects. The increase in competition occurs because there are more consumer segments that firms can cater to, and the firms can provide offerings that are more differentiated, leading to higher margins. The increase in the value of selects also occurs due to the larger variances of consumer preferences, meaning the degree to which some customers are good vs. bad matches for a particular offering is higher. Thus, heterogeneity in preferences can lead to a correlation between the competition measure and the probability of offering any particular select, even though no causal link exists. Of course, it is also possible that if there are more firms because each firm services a different niche, then the baseline lists themselves are already more targeted, leading to the selects having a lower value.

We provide evidence that this second form of endogeneity is not driving our results through difference-in-difference estimation using the 735 lists that appear in both 1997 and 2002. We regress the difference in the 2nd degree count variable (defined in Section 3.1) on the difference in the competition measure, the difference in the market size, and two indicator variables, which equal 1 if the list has moved to a larger or smaller size category, respectively. ${ }^{28}$ In contrast with the previous instrumental variable results, which rest on

\footnotetext{
${ }^{27} \mathrm{We}$ also ran probits where we omitted the market size variable from the analysis and instead used this variable as an instrument for competition, and obtained similar results. The advantage of this approach is that we can run this instrumental probit on the complete data set, and do it for both years. However, we cannot find a logical explanation of why this factor could not affect the decision to offer a select, so we do not report the results here in order to save space.

${ }^{28} \mathrm{We}$ cannot conduct difference-in-difference estimations for each of the selects individually because lists tend to continue offering selects after they first decide to add them, and the intersection of lists that appear in both years but did not offer recency selects in 1997, for example, is too small to have statistical significance. We cannot get the precise change in the size of the list because we only know the list size as falling in one of 8 categories.
} 
Table 9 Results-difference in difference specification

\begin{tabular}{lcc}
\hline & $\Delta(\#$ Selects $)$ & $\Delta(\#$ Selects $)$ \\
\hline$\Delta$ Log(CompMatch) & $0.295^{* * *}$ & \\
& $(0.091)$ & $0.007^{* * *}$ \\
$\Delta$ CompMatch & & $(0.002)$ \\
$\Delta$ Log(Mkt size $)$ & -0.011 & \\
& $(0.013)$ & 0.794 \\
$\Delta$ Mkt size $(\$ b)$ & & $(0.478)$ \\
List size smaller & $0.688^{* * *}$ & $.699^{* * *}$ \\
& $(0.107)$ & $(0.107)$ \\
List size larger & $0.390^{* * *}$ & $0.378^{* * *}$ \\
& $(0.112)$ & $(0.111)$ \\
Constant & $2.157^{* * *}$ & $2.096^{* * *}$ \\
& $(0.074)$ & $(0.077)$ \\
$\mathrm{N}$ & 735 & 735 \\
\hline
\end{tabular}

the assumption that the level of competition in a market in 1997 is a valid instrument for the level of competition in 2002, the difference-in-difference model relies on the alternative assumption that any industry conditions that affect both the competition measure and the select count remain unchanged from 1997 to $2002 .^{29}$ This assumption is likely weaker than the assumptions required for our cross-sectional analyses.

The results of this analysis, shown in Table 9, confirm our previous results; an increase in the competition measure is associated with an increase in the number of selects the mailing list offers. The results in the second column of this table confirms that the causality is not just the result of our functional form assumption. Further, the magnitude of the coefficient on competition in the difference-in-difference estimator is close to what we find when we run the cross-sectional analysis, adding additional support to our cross-sectional analysis based on the assumption that competition is exogenous to the decision to price discriminate. ${ }^{30}$

\subsection{Robustness checks}

To further test the robustness of our results, we consider four additional checks: whether the functional form of the competition measure affects our results, whether restricting the analysis to only large mailing lists affects the results, whether the results might be driven by factors in the largest industry (apparel) and whether our findings might be driven by the fact that firms in more-competitive industries just happen to hire more-aggressive marketing managers.

\footnotetext{
${ }^{29}$ More precisely, we assume that any unobservable industry fixed effects which are correlated with the competition measure change only in ways that are uncorrelated with the changes in the competition measures.

${ }^{30}$ If we estimate a regression of the number of selects on the variables in Tables 5 and 6 using OLS, the coefficients on competition are 0.24 and 0.30 for 1997 and 2002, respectively.
} 


\subsubsection{Competition measure}

Table 10 demonstrates that our results are robust to the precise way that we compute our competition measure. As described above, this table reports the differences in probabilities of price discriminating associated with the 90th percentile of competition compared to those associated with the 10th percentile.

The first line of this table reports the results for the baseline model. The next two lines show these same calculations using the alternative measures of competition, CompAve and CompCos, respectively. We see that, in general, the results are similar in magnitude and significance to the CompMatch results. This is true for both the 1997 data and the 2002 data.

\subsubsection{Large lists}

As referenced in Section 2.3, one potential issue is the degree to which heterogeneity within industry codes is left uncaptured by our competition measures. As one possibility, small lists might be specialty lists that appeal to different direct mailers than large lists do. To examine this issue, we reran our analysis using only lists that have more than 100,000 names. The fourth line in Table 10 reports these results. Generally, both the magnitude and statistical significance of the results are increased. In 1997, the coefficient on competition in the inquirers-only probit becomes significant but this change is not observed in 2002, suggesting that it is not a systematic change.

\subsubsection{Largest industry}

The histograms of our competition measure presented in Fig. 2 show a spike in competition at the high end of the distribution, which is due to the presence of many lists in the apparel industry. A skeptical reader might suspect that our results are mostly driven by the probability that mailing lists in the apparel industry choose to price discriminate. To address this concern, we estimate a model omitting all apparel lists. Reported in the fifth line in Table 10, the results are consistent with our main findings. While the magnitudes are slightly smaller, all but one of the effects (on the inquirers-only probit) are positive. The levels of significance are a little lower as well because there are fewer observations in this analysis, leading to higher standard errors.

\subsubsection{Managers}

Lastly, the final line in Table 10 presents the results if we include fixed effects for the different list managers. One might hypothesize that the results presented above are the result of the fact that a few large managers who happen to be in more competitive industries tend to be more likely to price discriminate. We would argue that even if this were true, this would not invalidate the robustness of our results. It is possible that those lists in very competitive 


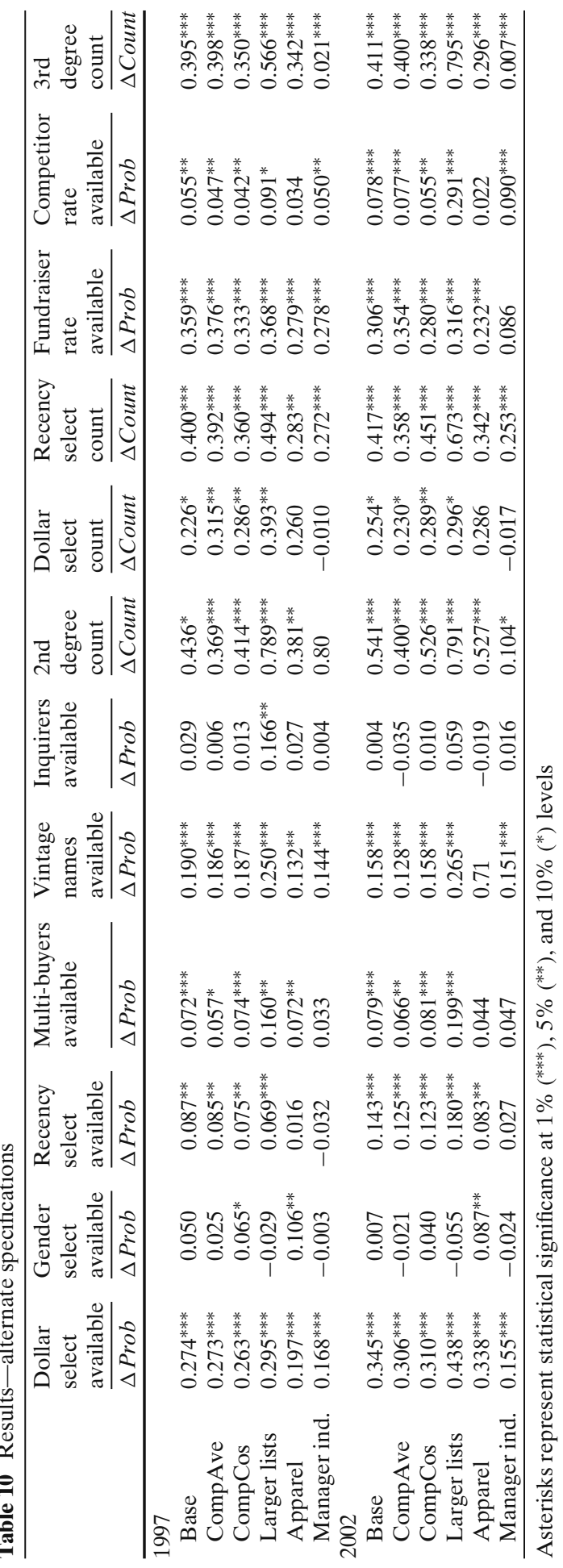


industries choose to go to large, sophisticated managers in order to compete more effectively.

Despite the fact that self-selection on the basis of competition towards managers who price discriminate is consistent with our story, we also test whether there is an addition effect of competition on the decision to price discriminate even after we control for the manager's identity. We do this by including indicator variables for each of the managers ${ }^{31}$ and find that the results are, for the most part, qualitatively similar, underscoring the strength of our results.

\section{Conclusion}

Theoretical ambiguity as to whether more-intense competition should lead to more or less price discrimination leaves the net impact as an empirical question. Mailing lists provide a good context in which to study this question because mailing lists are zero-marginal cost goods, meaning that differences in prices must be the result of demand, not cost. We find that greater competition leads to more second- and third-degree price discrimination and that greater competition is associated with a greater partition of the product space.

There are at least two explanations for this link. First, the increased probability of losing customers to competitors may trigger a prisoner's dilemma where firms pay the sunk costs required for price discrimination as modeled by Seim and Viard (2004). Second, increased competition can lead firms to price discriminate in order to extract surplus from those consumers who care a lot about cross-firm product differentiation while retaining those consumers who view products from different firms as close substitutes, as illustrated in a model by Chen et al. (2001).

While we cannot test which of these theories leads to our conclusion, it is interesting to note that we have some evidence that our results are consistent with the second theory. For example, the marketers who gain the most value from a multi-buyer select are those marketers who promote products that are similar to those offered in the catalog from which the mailing list was derived. These marketers are also the marketers who are most sensitive to product differentiation: The value they obtain from purchasing names from a list derived from a catalog selling very similar products compared to a list derived from a more distant product is high, while those marketers who are selling products that are only somewhat related to the underlying product do not care as strongly which list they purchase and are unlikely to pay for a multibuyer select. The argument for dollar selects is the same. The logic would apply to recency and vintage selects to the extent that people's purchasing patterns

\footnotetext{
${ }^{31}$ Because indicator variables for managers who have only one list would perfectly predict whether the client list price discriminates, we create an indicator variable for small managers, and assign this indicator for all managers that manage one or two lists.
} 
change more quickly than their underlying interests and that it is possible to target consumers with specific interests through a broader set of lists than one could use to target purchasing patterns. For third degree price discrimination, fundraisers probably see the various mailing lists as relative commodities, while marketers care about the catalog from which the mailing list was derived; Marketers representing direct competitors are the most sensitive to product differentiation between lists. In contrast, many firms sell products that appeal mostly to men or mostly to women. It is hard to make the argument, however, that the value of a gender select needs to be correlated with a firm's sensitivity to using one firm's mailing list as opposed to another firm's mailing list, which might explain why we find weaker results for the gender select than we find for the other variables.

Open Access This article is distributed under the terms of the Creative Commons Attribution Noncommercial License which permits any noncommercial use, distribution, and reproduction in any medium, provided the original author(s) and source are credited.

\section{References}

Anderberg, M. R. (1973). Cluster analysis for applications. New York: Academic.

Anderson, E. T., Fitzsimons, G., \& Simester, D. (2006). Measuring and mitigating the costs of stockouts. Management Science, 52(11), 1751-1763.

Anderson, E. T., Fong, N. M., Simester, D., \& Tucker, C. E. (2009a). How does an obligation to collect sales tax affect consumer and firm behavior? Journal of Marketing Research (in press).

Anderson, E. T., Hansen, K., \& Simester, D. (2009b). The option value of returns: Theory and empirical evidence. Marketing Science. doi:10.1287/mksc.1080.0430

Anderson, E. T., \& Simester, D. (2004). Long-Run effects of promotion depth on new versus established customers: Three field studies. Marketing Science, 23(1), 4-20.

Anderson, E. T., \& Simester, D. (2008). Does demand fall when customers perceive that prices are unfair: The case of premium pricing for large sizes. Marketing Science, 27, 492-500.

Arrow, K. J. (1962). Economic welfare and the allocation of resources for invention. In R. R. Nelson (Ed.), The rate and direction of inventive activity: Economic and social factors. National bureau of economic research, conference series (pp. 609-625). Princeton: Princeton University Press.

Asplund, M., Eriksson, R., \& Strand, N. (2008). Price discrimination in oligopoly: Evidence from Swedish newspapers. Journal of Industrial Economics, 56(2), 333-346.

Borenstein, S. (1985). Price discrimination in free-entry markets. RAND Journal of Economics, $16,380-397$.

Borenstein, S., \& Rose, N. L. (1994). Competition and price dispersion in the U.S. airline industry. Journal of Political Economy, 102(4), 653-683.

Borzekowski, R. (1999). The DMA list metrics report: A study of list brokers and managers. Washington, D.C.: Direct Marketing Association.

Bult, J. R., \& Wansbeek, T. (1995). Optimal selection for direct mail. Marketing Science, 14, 378-394.

Burnett, Ed. (1988). The complete direct mail list handbook: Everything you need to know about lists and how to use them for greater profit. Englewood Cliffs: Prentice Hall.

Busse, M., \& Rysman, M. (2005). Competition and price discrimination in yellow pages advertising. RAND Journal of Economics, 36(2), 378-390.

Chen, Y., Narasimhan, C., \& Zhang, Z. J. (2001). Individual marketing with imperfect targetability. Marketing Science, 20, 23-41.

Chintagunta, P. (2002) Investigating category pricing behavior at a retail chain. Journal of Marketing Research, 39, 141-154. 
Clerides, S. K. (2004). Price discrimination with differentiated products: Definition and identification. Economic Inquiry, 42(3), 404-412.

Cohen, A. (2008). Package size and price discrimination in paper towel market. International Journal of Industrial Organization, 26(2), 502-516.

Cohen, A., \& Kiser, E. K. (2007). Price discrimination in interest checking accounts. mimeo, Federal Reserve Board.

Corts, K. S. (1989). Third-degree price discrimination in oligopoly: All-out competition and strategic commitment. RAND Journal of Economics, 29(2), 306-323.

Desai, P. (2001). Quality segmentation in spatial markets: When does cannibalization affect product line design? Marketing Science, 20(3), 265-283.

Dogan, K., Haruvy, E., \& Rao, R. C. (2008). Who should practice price discrimination in an asymmetric duopoly. mimeo.

Draganska, M., \& Jain, D. C. (2006). Consumer preferences and product-line pricing strategies: An empirical analysis. Marketing Science, 25(2), 164-174.

Füsun, G., \& Ter Hofstede, F. (2006). How to compute optimal catalog mailing decisions. Marketing Science, 25(1), 65-74.

Gerardi, K., \& Shapiro, A. H. (2007). The effects of competition on price dispersion in the airline industry: A panel analysis. Federal Reserve Bank of Boston: Working paper, 07-7.

Graddy, K. (1995). Testing for imperfect competition at the fulton fish market. RAND Journal of Economics, 26(1), 75-92.

Johnson, J. P., \& Myatt, D. P. (2003). Multiproduct quality competition: Fighting brands and product line pruning. American Economic Review, 93(4), 748-774.

Katz, M. L. (1984). Price discrimination and monopolistic competition. Econometrica, 52, 14531472.

Miravete, E. J., \& Röller, L.-H. (2004). Competitive nonlinear pricing in duopoly equilibrium: The early US cellular telephone industry. mimeo.

Moorthy, S. (1984). Market segmentation, self selection, and product line design. Marketing Science, 3, 288-306.

Rochet, J.-C., \& Stole, L. A. (2002). Nonlinear pricing with random participation. The Review of Economic Studies, 69(1), 277-311.

Seim, K., \& Viard, V. B. (2004). The effect of entry and market structure on cellular pricing tactics. mimeo.

Shaffer, G., \& Zhang, Z. J. (1995). Competitive coupon targeting. Marketing Science, 14, 395-416.

Shepard, A. (1991). Price discrimination and retail configuration. The Journal of Political Economy, 99(1), 30-53.

Simester, D., Sun, P., \& Tsitsiklis, J. (2006). Dynamic catalog mailing policies. Management Science, 52(2), 683-696.

Stavins, J. (2001). Price discrimination in the airline market: The effect of market concentration. The Review of Economics and Statistics, 83(1), 200-202.

Steenburgh, T. J., Ainslie, A., \& Engebretson, P. H. (2003). Massively categorical variables: Revealing the information in zip Codes. Marketing Science, 22, 40-57.

Stigler, G. J. (1952). The theory of price. New York: Macmillan.

Stole, L. A. (1995). Nonlinear pricing and oligopoly. Journal of Economics \& Management Strategy, 44(4), 529-562.

Stole, L. A. (2003). Price discrimination and imperfect competition. mimeo.

Tirole, J. (1988) The theory of industrial organization. Cambridge: MIT.

Varian, H. R. (1989). Price discrimination. In R. Schmalensee, \& R. D. Willig (Eds.), Handbook of industrial organization (Vol. I, chapter 10, pp. 598-654). Amsterdam: Elsevier.

Villas-Boas, J. M., \& Schmidt-Mohr, U. (1999). Oligopoly wiht asymmetric information: Differentiation in credit markets. RAND Journal of Economics, 30, 375-396.

Yang, H., \& Ye, L. (2008). Nonlinear pricing, market coverage, and competition. Theoretical Economics, 3(1), 123-153. 